\title{
United Kingdom Prospective Diabetes Study (UKPDS)
}

National Diabetes Information Clearinghouse (NDIC)

\section{Definitions}

Type 2 diabetes

Defined by National Diabetes Information Clearinghouse (NDIC)

Blood glucose

Defined by National Diabetes Information Clearinghouse (NDIC)

Kidney

Defined by National Diabetes Information Clearinghouse (NDIC)

Blood pressure

Defined by National Diabetes Information Clearinghouse (NDIC)

Hypertension

Defined by National Diabetes Information Clearinghouse (NDIC)

Stroke

Defined by National Diabetes Information Clearinghouse (NDIC)

Complications

Defined by National Diabetes Information Clearinghouse (NDIC)

\section{Source}

National Diabetes Information Clearinghouse (U.S.). (2009). The diabetes dictionary. [Bethesda, Md.]: U.S. Dept. of Health and Human Services, National Institutes of Health, National Institute of Diabetes and Digestive and Kidney Diseases, National Diabetes Information Clearinghouse.

A British study conducted from 1977 to 1997 in people with type 2 diabetes. The study showed that if people lowered their blood glucose, they lowered their risk of eye disease and kidney damage. In addition, those with type 2 diabetes and hypertension who lowered their blood pressure also reduced their risk of stroke, eye damage, and death from long-term complications. 